\title{
Analysis on Corruption and Collusive Behaviors in Government Procurement in a Game Theory Perspective
}

\author{
Associate Prof. Xiaoyan Hao \\ Management College, Inner Mongolia University of Technology \\ 49 Aimin Road, Xincheng District, Huhhot 010051, Inner Mongolia, China \\ Tel: +86-136-9471-2449Ｅ-mail: haoxiaoyanyan@163.com \\ Peixiao Qi (Corresponding author) \\ Department of Economics, Management College \\ Inner Mongolia University of Technology \\ 49 Aimin Road, Xincheng District, Huhhot 010051, Inner Mongolia, China \\ Tel: +86-159-4721-0861 E-mail: qipeixiao@foxmail.com
}

Received: April 7, $2011 \quad$ Accepted: May 16, $2011 \quad$ doi:10.5430/jms.v2n2p38

This research is financed by Applied Technology Research and Development Fund Project: Applied Research on Government Procurement Institutions of Stimulating Independent Innovation in Public Finance System (No. 20100918, Person in charge: Xiaoyan Hao) and Applied Technology Research and Development Fund Project: Analysis on Independent Innovation Product Management Mechanism and Government Procurement Management System (No. 20090819, Person in charge: Xiaoyan Hao).

\begin{abstract}
Government Procurement is an important measure by which the government can guide economic development direction, protect and support national (or local) industry and implement macro-economic control. This paper analyzes corruption and collusive behaviors in government procurement practice in a Game Theory perspective. First, using Willenbrock's bidding model to analyze the rent-seeking behavior in government procurement. Second, using game model to analyze procurement officials' corruption and collusive behavior. Third, using game model to analyze suppliers' collusive behavior. Finally, this paper proposes some corresponding solutions in each part based on game model analysis.
\end{abstract}

Key words: Government procurement, Corruption and collusive behaviors, Game Model

\section{Introduction}

Economic Man Hypothesis, whether in classical economics or in neoclassical economics, captures the characteristics of individuals and enterprises in economic activities and has become the premise of all economic studies.

In government procurement activity, for suppliers, their behaviors fully consistent with Economic Man Hypothesis and their activities include legitimate competition and bribery, rent-seeking and other illegal behaviors. For procurement officials, after they meet the supervision from authorities and the public, they will use the remaining rights to positively exchange currency in order to maximize their own utility. So, it is the characteristics of Economic Man that lead to various corruption phenomena.

According to estimation by experts, in China, at present, the proportion of total amount of all rent-seeking on GNP has reached $20 \%-40 \%$, much higher than the two most corrupt countries in 1970s-India and Turkey-their proportions respectively are $7.3 \%$ and $15 \%$. This fact means that a third of material wealth produced by people across the country in a year has become rent-seekers and corrupt officials' income. Because China is being in a special economic transition period when a large number of public ownership enterprises are transition to private ownership enterprises and planned economy is transition to market economy, the rent-seeking phenomena, especially the power rent-seeking activities, are more and more difficult to avoid. In government procurement, the rent-seeking, particularly "power rent-seeking", has been more alarming. 
In practice, there is a long principal-agent chain include five subjects: taxpayer, government, financial department, specialized government procurement agency and procurement official. When principal and agent's utility functions are inconsistent, principal-procurement official-goes against government procurement laws or regulations, which will lead to procurement collusive behavior. Besides, the severe asymmetric information can also lead to procurement collusive behavior and the incomplete principal supervision and opportunism make principal-agent deviated in procurement activity.

So, how to eliminate or reduce the probability of collusive behavior plays an important role in practical procurement activity. The following three perspectives analysis are meaningful.

\section{Game analysis on rent-seeking behavior}

\subsection{Theoretical model on rent-seeking behavior}

Based on statements in "Introduction" section, author thinks reasonable system can be designed to solve rent-seeking according to Economic Man Hypothesis. In government procurement practice, procurement officials will use their rights to set rent, so suppliers' rent-seeking behaviors have become the most common corruption form. Now, game analysis on rent-seeking behavior is as following:

Author uses Willenbrock's bidding model (proposed in 1973) to analyze the rent-seeking behavior in government procurement (Yang Canming \& Li Jingyou, 2004, pp. 41-50). This model thought various offer price levels $x_{i}$ mean various action plans, the offer price given includes "win" and "non-win" ( $\beta_{1}$ means "win", $\beta_{2}$ means "non-win"), $V\left(x_{i}, \beta_{j}\right)$ means the final value when offer price is $x_{i}$ and $\beta_{j}$ happens whose probability is $p\left(\beta_{j}\right)$, so suppliers' offer price should follow this constraint:

$$
\max \left[p\left(\beta_{1}\right) V\left(x_{i}, \beta_{1}\right)+p\left(\beta_{2}\right) V\left(x_{i}, \beta_{2}\right)\right]
$$

There are only "win" or "non-win" after giving offer price, so $p\left(\beta_{1}\right)+p\left(\beta_{2}\right)=1$. We suppose suppliers don't gain any value when they fail, that is $V\left(x_{i}, \beta_{2}\right)=0$. So Equation (2-1) can be simplified as:

$$
\max \left[p\left(\beta_{1}\right) V\left(x_{i}, \beta_{1}\right)\right]
$$

Therefore, when there is no rent-seeking, suppliers' expected utility is:

$$
E U_{N}=p\left(\beta_{1}\right) V\left(x_{i}^{*}, \beta_{1}\right)
$$

For Equation (2-3), $x_{i}^{*}$ is the equilibrium offer price which makes suppliers' expected utility maximized. Its first-order condition and second-order condition respectively are:

$$
\begin{aligned}
& -p\left(\beta_{1}\right) V^{\prime}\left(x_{i}^{*}, \beta_{1}\right)=0 ; \\
& \text { - } p\left(\beta_{1}\right) V^{\prime \prime}\left(x_{i}^{*}, \beta_{1}\right) \leq 0 .
\end{aligned}
$$

When there is rent-seeking, we also necessarily introduce other two variables. Suppose $p^{m}$ means the marginal probability which is led by bribery and is more likely to win when rent-seeking and suppose $C$ means rent-seeking cost, so, now, suppliers' offer price should follow this constraint:

$$
\max \left[\left(p\left(\beta_{1}\right)+p^{m}\right)\left(V\left(x_{i}, \beta_{1}\right)-C\right)+\left(p\left(\beta_{2}\right)-p^{m}\right)(-C)\right]
$$

Then, this time, when there is rent-seeking, suppliers' expected utility is:

$$
E U_{m}=\left[\left(p\left(\beta_{1}\right)+p^{m}\right)\right]\left[\left(V\left(x_{i}^{* *}, \beta_{1}\right)-C\right]+\left[\left(p\left(\beta_{2}\right)-p^{m}\right](-C)\right.\right.
$$

For Equation (2-5), $x_{i}^{* *}$ is the equilibrium offer price which makes suppliers' expected utility maximized. Its first-order condition and second-order condition respectively are:

$$
\begin{aligned}
& -\left[p\left(\beta_{1}\right)+p^{m}\right] V^{\prime}\left(x_{i}^{* *}, \beta_{1}\right)=0 ; \\
& -\left[p\left(\beta_{1}\right)+p^{m}\right] V^{\prime \prime}\left(x_{i}^{* *}, \beta_{1}\right) \leq 0 .
\end{aligned}
$$


For procurement officials, we make four supposes as following:

$-r$ means their benefit when integrity procurement and success and they will not be punished when they fail to purchase.

$-r_{e}$ means extra benefit when rent-seeking.

${ }^{-} r_{e}$ means punishment when their corruption behavior is found ( $K$ means punishment coefficient).

- $p_{E}$ means exposure probability of their corruption behavior.

Therefore, when there is no rent-seeking, procurement officials' expected utility is:

$$
E U=r
$$

When there is rent-seeking, procurement officials' expected utility is:

$$
E U_{E}=\left(1-p_{E}\right)\left(r+r_{e}\right)+p_{E}\left(-K r_{e}\right)
$$

According to above analysis, we can provide following game matrix model whether suppliers and procurement officials seek rent or not, the result is shown in Table 1.

\section{$<$ Table 1 about here $>$}

In game matrix model, A-space means suppliers and procurement officials are in collusion. D-space means suppliers and procurement officials are not in collusion. B-space means suppliers are collusive but procurement officials are not collusive. Suppliers cannot gain collusive utility, so their utility is the same as D-space; for procurement official, because suppliers are collusive, they will gain some benefits, that is some bribery, but less than the collusive utility in A-space. $\mathrm{C}$-space means suppliers are not collusive but procurement officials are collusive. At this time, suppliers will not gain the project they want, which makes their utility is 0 ; but procurement officials can be collusive with other suppliers, because of rent-seeking cost, their utility will be less than the utility in A-space.

But the optimal solution in Table 1 is uncertain. For procurement officials, their driving force of collusion comes from $E U_{E}>E U$, make

$$
\begin{aligned}
\Delta E U_{\text {procurement tfficals }} & =E U_{E}-E U=\left(1-p_{E}\right)\left(r+r_{e}\right)+p_{E}\left(-K r_{e}\right)-r \\
& =r_{e}\left(1-p_{E}-K p_{E}\right)-p_{E} r
\end{aligned}
$$

Based on Equation (2-8), the bigger $K$ (punishment coefficient) and $p_{E}$ (exposure probability) are, the smaller $\triangle E U_{\text {procurement officals }}$ is. So strengthening supervision and punishment is necessary.

For suppliers, their driving force comes from $E U_{M}>E U_{N}$, make

$$
\begin{aligned}
\Delta E U_{\text {suppliers }}= & E U_{M}-E U_{N}=\left[\left(p\left(\beta_{1}\right)+p^{m}\right)\right]\left[V\left(x_{i}^{* *}, \beta_{1}\right)-C\right]+\left[\left(p\left(\beta_{2}\right)-p^{m}\right)\right](-C) \\
& -p\left(\beta_{1}\right) V\left(x_{i}^{*}, \beta_{1}\right) \\
= & p\left(\beta_{1}\right)\left[V\left(x_{i}^{* *}, \beta_{1}\right)-V\left(x_{i}^{*}, \beta_{1}\right)\right]+p^{m} V\left(x_{i}^{* *}, \beta_{1}\right)-C\left[p\left(\beta_{1}\right)+p\left(\beta_{2}\right)\right]
\end{aligned}
$$

As $p\left(\beta_{1}\right)+p\left(\beta_{2}\right)=1$, Equation (2-9) is simplified:

$$
\Delta E U_{\text {suppliers }}=p\left(\beta_{1}\right)\left[V\left(x_{i}^{* *}, \beta_{1}\right)-V\left(x_{i}^{*}, \beta_{1}\right)\right]+p^{m} V\left(x_{i}^{* *}, \beta_{1}\right)-C
$$

For Equation (2-10), $V\left(x_{i}^{* *}, \beta_{1}\right)-V\left(x_{i}^{*}, \beta_{1}\right)$ is decided by suppliers' utility and difficult to control. But we can clearly know that the smaller $p^{m}$ (marginal probability which is led by bribery) is and the bigger $C$ (rent-seeking cost) is, the smaller $\Delta E U_{\text {suppliers }}$ is.

So strengthening supervision (decrease $p^{m}$ ) and designing a reasonable remuneration mechanism (increase $C$ ) are very effective to prevent collusive behavior.

\subsection{Practice measure}

According to the game model analysis in 2.1, we can take two practice measures as following to eliminate or reduce the probability of collusive behavior (rent-seeking):

(i) Strengthen supervision and punishment to eliminate or reduce the probability of rent-seeking;

(ii) Design reasonable a remuneration mechanism, at the same time, carry out centralized procurement to eliminate or reduce the probability of rent-seeking. 


\section{Game analysis on procurement officials' collusive behavior}

\subsection{Theoretical model on procurement officials' collusive behavior}

Officials' collective collusion is one of the results of rent-seeking behavior, now, game analysis on procurement officials' collusive behavior is as following:

In officials' collective collusion, decision-maker is in key position. We suppose procurement officials can gain total rent $R$ when they are collusive with suppliers, $R_{1}$ is the income of decision-maker $N_{1}$, a number of collusive persons is $n$. We also suppose the collusive persons will gain equal income, so the income belongs to the $i^{\text {th }}$ collusive person is $\frac{R-R_{1}}{n-1}$.

Then, make $p$ is the probability of successful collusion, $L_{i}$ is the loss of the $i^{\text {th }}$ collusive person who is revealed. So, the decision-maker's expected utility is (Zou Jinwen, 2002, pp. 25-28):

$$
E U_{1}=p R_{1}+(1-p)\left(R_{1}-L_{1}\right)
$$

For other each collusive person, the probability of his successful collusion $q_{i}$ is not only related with $p$ but also with the confidence between him and other collusive persons except him, then, make $q_{i}=p \prod_{j}^{n-1} \alpha_{i j}, \alpha_{i j}$ is the $i^{\text {th }}$ procurement official's confidence to the ${ }_{j}^{\text {th }}$ procurement official, at the same time, make each $\alpha_{i j}$ is equal, that is $\prod_{j}^{n-1} \alpha_{i j}=\alpha^{n-1}$. Therefore, the collusive person's expected utility is (Zhang Derang, 2004, pp. 30-32):

$$
E U_{i}=p \alpha^{n-1} \frac{R-R_{1}}{n-1}+\left(1-p \alpha^{n-1}\right)\left(\frac{R-R_{1}}{n-1}-L_{i}\right)
$$

In one-time collusion, the game matrix model of decision-maker and collusive persons is shown in Table 2 .

$<$ Table 2 about here $>$

A-space means decision-maker and collusive persons are in collusion. D-space means decision-maker and collusive persons are not in collusion (don't consider their integrity income). B-space means collusive persons don't cooperate, C-space means decision-maker doesn't cooperate.

In Table 2, $E U_{W}$ means officials' normal expected utility, which is general fixed wage.

\subsection{Practice measure}

According to the game model analysis in 3.1, we can take three practice measures as following to eliminate or reduce the probability of procurement officials' collusive behavior:

(i) Use high wage to stimulate integrity, at the same time, punishment must be severe enough. Because $E U_{1}>E U_{W}$ and $E U_{i}>E U_{W}$ are the necessary conditions which make procurement officials collusive, we should make $E U_{1}<E U_{W}$ and $E U_{i}<E U_{W}$ as far as possible and make $E U_{W}$ is as big as possible in order to eliminate or reduce the probability of procurement officials' collusion. According to Equation (3-1) and Equation (3-2), we know the bigger $L_{i}$ is, the smaller $E U_{1}$ and $E U_{i}$ are, the better procurement behavior is.

(ii) Rights can not be too concentrated. According to $E U_{i}$, a number of collusive persons should not be too many, otherwise, $n$ is too big, which makes $E U_{i}$ sharply reduce and collusion not easily form. So rights must be properly distributed, that is $n$ must be big enough.

(iii) Maintain the proper movement of persons within the section. In one-time collusion, the confidence among persons is very important, if some persons work in the same section for a long time, interest groups are easy to form, which is 
conducive to collusion. When there are new persons in some section, confidence among persons will drastically reduce, that is the smaller $\alpha$ is, the smaller $E U_{1}$ and $E U_{i}$ are. Now, one-time game is equivalent to "Prisoner Dilemma", in this condition, the result of one-time game tends to Nash Equilibrium, that is D-space shown in Table 2. Therefore, Maintaining the proper movement of persons within the section is of very important practical significance to prevent collective collusion.

\section{Game analysis on suppliers' collusive behavior}

\subsection{Theoretical model on suppliers' collusive behavior}

For suppliers' collusion, if we are ready to analyze it in details, we must consider lots of factors. If like that, the analysis will be very complex, so we will only make general analysis.

In suppliers' collusion, there must be a organizer, suppose he is $N_{1}$. And other suppliers are participants, suppose they are $N_{i}$, a number of whom are $n-1$. We also suppose the available profit of normal procurement project is $R$ and the collusive profit of organizer is $R^{\prime}\left(R^{\prime}>R\right)$ when suppliers are in collusion. $p$ is the probability suppliers can gain the procurement project under the free-competition conditions (suppose each $p$ is equal). Therefore, when suppliers are not in collusion, the organizer and other suppliers' expected utility respectively are:

$$
\begin{aligned}
E_{N_{1}} & =p R \\
E_{N_{i}} & =p R
\end{aligned}
$$

$E_{N_{1}}$ means the organizer's $\left(N_{1}\right)$ expected utility when he is not in collusion, $E_{N_{i}}$ means other suppliers' $\left(N_{i}\right)$ expected utility when they are not in collusion.

We suppose $q$ is the probability of suppliers' successful collusion, similar to 3.1, $q$ is related with the confidence among suppliers, suppose the confidence is $\gamma$ and each $\gamma$ is equal, so $q=\prod_{j}^{n} \gamma_{i j}=\gamma^{n}, \gamma_{i j}$ is the $i^{\text {th }}$ supplier's confidence to the $j^{\text {th }}$ supplier.

If the collusion is successful, the organizer will gain procurement project and gain collusive profit $R^{\prime}$. We suppose organizer's collusive cost is $C$, that is the benefit which the organizer provides to other collusive suppliers. Therefore, when organizer is in collusion, his expected utility is:

$$
\hat{E}_{N_{1}}=R^{\prime}(1-p) \prod_{j}^{n-1} \gamma_{i j}-C=R^{\prime}(1-p) \gamma^{n-1}-C
$$

For other collusive suppliers, they don't gain the procurement project, but they will gain the benefit which the organizer provides. We suppose other collusive suppliers' collusive benefit is equal, so their expected utility is:

$$
\hat{E}_{N_{i}}=\frac{C}{n-1}(1-p) \prod_{j}^{n-1} \gamma_{i j}=\frac{C}{n-1}(1-p) \gamma^{n-1}
$$

The game matrix model of organizer and other collusive suppliers is shown in Table 3.

$<$ Table 3 about here $>$

A-space means organizer and other suppliers are in collusion. D-space means organizer and other suppliers are not in collusion, at this time, their expected utility is the utility under the free-competition conditions. C-space means organizer is not in collusion but other suppliers are in collusion, at this time, because of betrayal of the organizer, he can gain the procurement project at a lower price; other collusive suppliers' expected utilities are all zero. B-space means organizer is in collusion but other suppliers are not in collusion, at this time, because of betrayal of other collusive suppliers, the organizer cannot gain the procurement project and his expected utility is zero; but other collusive suppliers cannot guarantee that they all don't betray each other, so their expected utility is equivalent to the utility under the free-competition conditions.

For the theoretical model, D-space is Nash Equilibrium; but in the actual bid, because of infighting among suppliers, the confidence among them is very low. The organizer is fear of other collusive suppliers' betrayal, which makes him fall into B-space, so he is most likely to betray firstly. Similarly, each collusive supplier is also fear of organizer's betrayal, 
which makes them fall into C-space, so they are most likely to betray firstly. Therefore, in "Prisoner Dilemma" like this, D-space is the best equilibrium, that is all suppliers are not in collusion.

However, the possibility of collusion still exists. For organizer, his driving force of collusion comes from $\hat{E}_{N_{1}}>E_{N_{1}}$; for other collusive suppliers, their driving force comes from $\hat{E}_{N_{i}}>E_{N_{i}}$. Make

$$
\begin{gathered}
\Delta E_{N_{1}}=\hat{E}_{N_{1}}-E_{N_{1}}=R^{\prime}(1-p) \gamma^{n-1}-C-p R=-p\left(R^{\prime} \gamma^{n-1}+R\right)+R^{\prime} \gamma^{n-1}-C \\
\Delta E_{N_{i}}=\hat{E}_{N_{i}}-E_{N_{i}}=\frac{C}{n-1}(1-p) \gamma^{n-1}-p R=-p\left(\frac{C}{n-1} \gamma^{n-1}+R\right)+\frac{C}{n-1} \gamma^{n-1}
\end{gathered}
$$

When $\Delta E_{N_{1}}>0$ and $\Delta E_{N_{i}}>0$, the collusion is likely to happen. Now, we make $\Delta E_{N_{1}}=0$ and $\Delta E_{N_{i}}=0$, so, according to Equation (4-5) and Equation (4-6), we can see $C$ as a function of $p$, that is:

$$
\begin{gathered}
\Delta E_{N_{1}}=0 \Rightarrow C=-p\left(R^{\prime} \gamma^{n-1}+R\right)+R^{\prime} \gamma^{n-1} \\
\Delta E_{N_{i}}=0 \Rightarrow C=\frac{p}{1-p} \cdot \frac{(n-1) R}{\gamma^{n-1}}
\end{gathered}
$$

We can draw function graph based on Function (4-7) and Function (4-8), it is shown in Figure 1.

\section{$<$ Figure 1 about here $>$}

In Figure 1, $\Delta E_{N_{1}}$ is the function graph of Function (4-7) and $\Delta E_{N_{i}}$ is the function graph of Function (4-8).

According to Linear Programming, there are $\Delta E_{N_{1}}>0$ and $\Delta E_{N_{i}}>0$ in area of crooked triangle OST, which is the collusive area. Suppliers' collusion happens in area where the probability $p$ is lower, that is collusion will possibly happen when suppliers generally consider the probability of their winning is lower under the free-competition conditions.

As suppliers' winning confidence is increasing under the free-competition conditions and the cost which organizer is willing to provide is smaller and smaller but the "benefits" which collusive participants want to gain is more and more, the collusion among suppliers is less and less likely to happen (there is more and more chance to escape from the area of crooked triangle OST).

\subsection{Practice measure}

According to the game model analysis in 4.1, we can take two practice measures as following to eliminate or reduce the probability of suppliers' collusive behavior:

(i) Create an open competitive environment to the greatest extent.

(ii) Pay attention to the appropriate confidentiality and security measures. Under the free-competition conditions, each supplier's establishment of his own winning probability will not be too low, therefore, the probability of the collusion among many similar strength suppliers is lower and lower, which is very practical significance to maintain a appropriate bid scale and confidentiality of commercial information.

\section{Conclusion}

This paper analyzes three collusive behaviors in government procurement in a game theory perspective. Firstly, this paper uses Willenbrock's bidding model to analyze the rent-seeking behavior in government procurement, whose result is: strengthening supervision and punishment, at the same time, designing reasonable payment mechanism and carrying out centralized procurement can eliminate or reduce the probability of collusive behavior (rent-seeking). Secondly, this paper analyzes procurement officials' collusion behaviors in government procurement, whose results are: (i) using high wage can stimulate integrity, at the same time, punishment must be severe enough; (ii) rights can not be too concentrated; (iii) it is a must to maintain the proper movement of persons within the section. Thirdly, this paper analyzes suppliers' collusion behaviors in government procurement, whose results are: (i) to create an open competitive environment to the greatest extent; (ii) to maintain a appropriate bid scale and pay attention to the appropriate confidentiality and security measures. 


\section{References}

Ai, Jiafeng (2011). Research of prevention mechanism of library books procurement corruption. Library, (1): 118-119. doi:CNKI:SUN:TSGT.0.2011-01-042, http://dx.doi.org/ CNKI:SUN:TSGT.0.2011-01-042

Chen, Xuenan (2011). Procurement management and game theory factor. Petroleum \& Petrochemical Material Procurement, (2):70. doi:CNKI:SUN:HGZL.0.2011-02-030, http://dx.doi.org/ CNKI:SUN:HGZL.0.2011-02-030

Dong, Yuan (2009). Research on the standardization of government procurement in China. Dissertation for the master degree of Dalian University of Technology. doi:CNKI:CDMD:2.2010.021599, http://dx.doi.org/ CNKI:CDMD:2.2010.021599

Gary E. Bolton (2002). Game theory's role in role-playing. International Journal of Forecasting, 18 (3): 353-358.doi:10.1016/S0169-2070(02)00027-4, http://dx.doi.org/10.1016/S0169-2070(02)00027-4

John Pierce (2004). NSW government procurement policy. [online] Available: http://www.treasury.nsw.gov.au/ (April 6, 2010).

Liu, Jianming (2009). The study on control of government procurement tender. Dissertation for the master degree of Yanshan University. doi:CNKI:CDMD:2.2010.018054, http://dx.doi.org/ CNKI:CDMD:2.2010.018054

$\mathrm{Li}$, Yongbin (2010). The existing problems and countermeasures in China government procurement. Dissertation for the master degree of Fiscal Science Institute of Finance Ministry. doi:CNKI:CDMD:2.2010.240774, http://dx.doi.org/CNKI:CDMD:2.2010.240774

Maria Garcia-Alonso \& Paul Levine (2008). Strategic procurement, openness and market structure. International Journal of Industrial Organization, 26 (5): 1180-1190. doi: 10.1016/j.ijindorg.2007.12.003, http://dx.doi.org/10.1016/j.ijindorg.2007.12.003

Roderica Taduran Stamer (2006). Reducing costs of exchange by combating corruption in procurement. The $10^{\text {th }}$ ISNIE Conference at Boulder, Colorado on 21-24 September 2006.

Tan, Yiran, Shi, Zhuxian, Zhao, Hongqiang \& Meng, Lingli (2011). Review of game theory development. Business Research, (2): 78-79. doi:CNKI:SUN:QYYJ.0.2011-03-025, http://dx.doi.org/CNKI:SUN:QYYJ.0.2011-03-025

Yang, Canming \& Li, Jingyou (2004). Research on government procurement. Beijing: Economic Science Press. pp. 41-50.

Yu, Qinhua (2010). A risk prevention mechanism for honest and clean administration in government procurement. Chinese Journal of Tropical Agriculture, 30 (12): 47-51. doi:CNKI:SUN:RDNK.0.2010-12-018, http://dx.doi.org/CNKI:SUN:RDNK.0.2010-12-018

Yue, Lingyun (2010). Game theory and its application in decision research. Guide Journal of Science \& Education, (35): 98, 115. doi:CNKI:SUN:KJDK.0.2010-12-058, http://dx.doi.org/CNKI:SUN:KJDK.0.2010-12-058

Zou, Jinwen (2002). Economic perspective on government procurement. Contemporary Finance \& Economy, (2): 25-28. doi:cnki:ISSN:1005-0892.0.2002-02-005, http://dx.doi.org/cnki:ISSN:1005-0892.0.2002-02-005

Zhang, Derang (2004). The rent-seeking behavior and its containment in government procurement expenditure. China Government Procurement, (6): 30-32. doi:cnki:ISSN:1671-0665.0.2004-06-006, http://dx.doi.org/cnki:ISSN:1671-0665.0.2004-06-006 
Table1. Game matrix model about suppliers and procurement officials

\begin{tabular}{|c|c|c|c|}
\hline & & \multicolumn{2}{|c|}{ Procurement officials } \\
\hline & & Collusion & Non-collusion \\
\hline \multirow{2}{*}{ 告 } & Collusion & $\begin{array}{c}\mathrm{A} \\
E U_{m}, E U_{E}\end{array}$ & $\begin{array}{c}\text { B } \\
E U_{N}, \text { less than } E U_{E}\end{array}$ \\
\hline & Non-collusion & $\begin{array}{c}\text { C } \\
\text { 0, less than } E U_{E}\end{array}$ & $\begin{array}{c}\mathrm{D} \\
E U_{N}, E U\end{array}$ \\
\hline
\end{tabular}

Table 2. Game matrix model about decision-maker and collusive persons in procurement officials

\begin{tabular}{|c|c|c|c|}
\hline & & \multicolumn{2}{|c|}{ Collusive persons } \\
\hline & & Collusion & Non-collusion \\
\hline \multirow{2}{*}{ 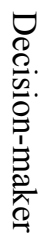 } & Cooperation & $\begin{array}{c}\mathrm{A} \\
E U_{1}, E U_{i}\end{array}$ & $\begin{array}{c}\text { B } \\
\text { Less than } E U_{1}, E U_{W}\end{array}$ \\
\hline & Non-cooperation & $\begin{array}{c}\text { C } \\
E U_{W}, \text { less than } E U_{i}\end{array}$ & $\begin{array}{c}\mathrm{D} \\
E U_{S}, E U_{W}\end{array}$ \\
\hline
\end{tabular}

Table 3. Game matrix model about organizer and collusive persons in suppliers

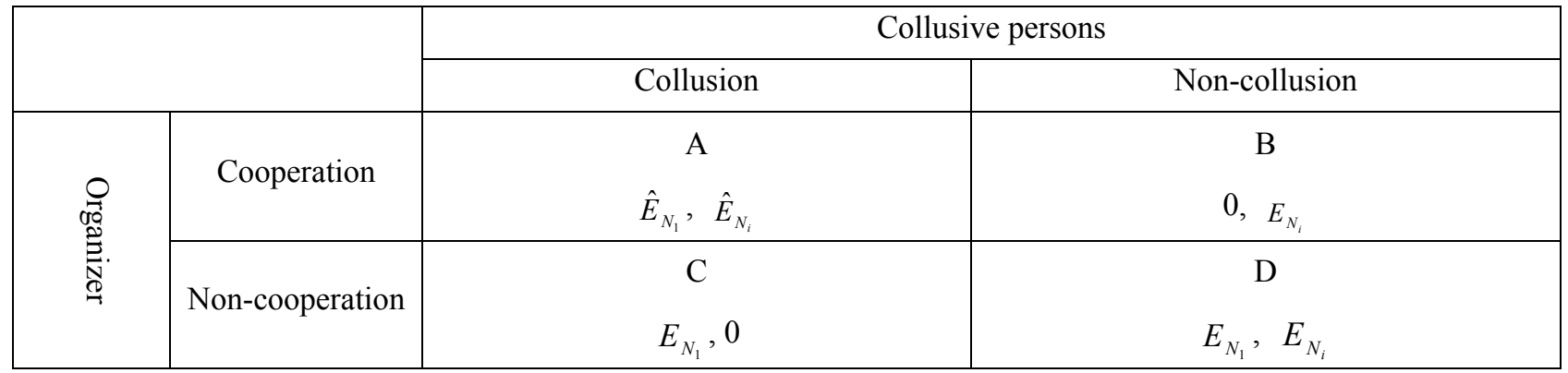

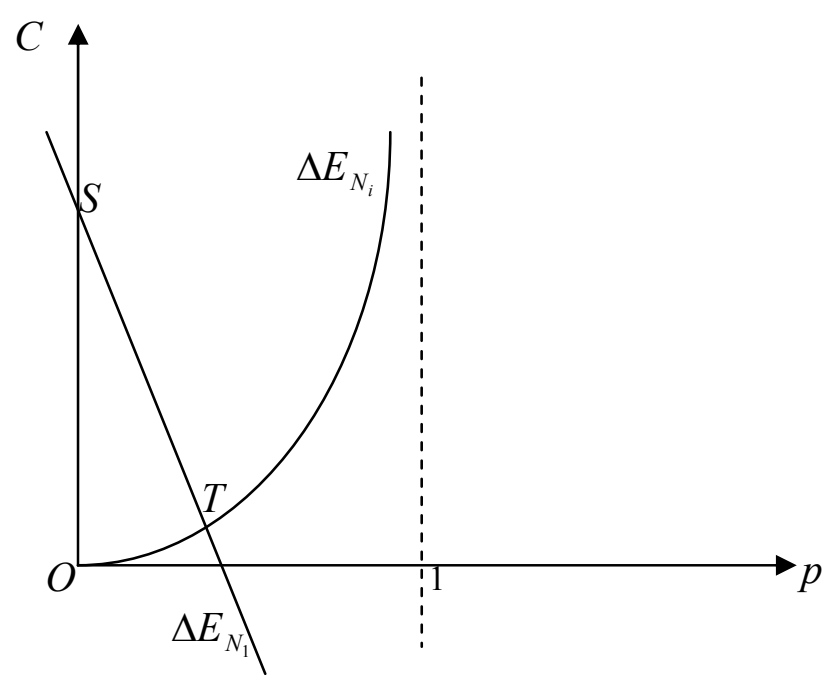

Figure 1. The function graph $(\mathrm{C}-\mathrm{p}$ Graph) 